\title{
Repair of the total anomalous pulmonary venous connection
}

\section{Correção da conexão anômala total de veias pulmonares}

Ulisses Alexandre CROTI ${ }^{1}$, Domingo Marcolino BRAILE ${ }^{1}$, Camilo Ernesto Viana FRITZ ${ }^{1}$, Carlos Henrique DE MARCHI $^{1}$

RBCCV 44205-1087

\section{CHARACTERIZATION OF THE PATIENT}

3-month and 27-day-old male child, $4.4 \mathrm{~kg}$, born in Rosana, SP. Preterm birth at 36 weeks, $2.6 \mathrm{~kg}$, had cyanosis on the first day of life, requiring care of neonatal intensive care for six days.

The patient developed whimpering, tachydyspnea and difficult in sucking. Outpatient echocardiography at 15 days of life was requested, but due to lack of skilled professionals and the difficulty of vacancies by the Unified Health System, it was only performed after 2 months [1].

With the significant worsening of the signs of congestive heart failure, the child was emergently referred to the Hospital de Base of São José do Rio Preto.

The preoperative echocardiogram in our Service revealed supracardiac type total anomalous connection of pulmonary veins, with the pulmonary veins converging into a common vein (collector sac) located posteriorly to the left atrium (LA), which drained into a vertical vein that flew into the innominate vein. Such vein, in its turn, flew into the superior vena cava (SVC). Doppler revealed a pervious foramen ovale with flow from right to left without restriction, severe pulmonary hypertension with right ventricular systolic pressure of $67 \mathrm{mmHg}$, in addition to systolic turbulent flow in right atrium (RA) compatible with functional tricuspid insufficiency.

Surgical correction consisted basically of anastomosis between the hypoplastic LA and the collector sac, vertical section of the vein, resection of the oval fossa and closure

THE VIDEO PERTINENT TO THE TEXT IS AVAILABLE ON THE BJCVS WEBSITE: http://www.rbccv.org.br

CONFLICT OF INTEREST STATEMENT:

The authors declare that they have conflict of interests; Braile Biomédica ${ }^{\circledR}$ provided the material used and supplied the video images of the operation, presenting its commercial products.

1. São José do Rio Preto Pediatric Cardiovascular Surgery Service Hospital de Base - São José do Rio Preto Medical School, SP, Brazil. of interatrial communication (IAC) with a bovine pericardium patch $[2,3]$. The time of cardiopulmonary bypass (CPB) was 129 minutes, myocardial ischemia 54 minutes and the total circulatory arrest was of 31 minutes at $20^{\circ} \mathrm{C}$.

\section{DESCRIPTION OF THE TECHNIQUE USED}

Skin incision, opening of the subcutaneous tissue with electrical scalpel and median sternotomy.

Exposure of the anterior mediastinum, opening of the pericardial sac with its attachment to the chest walls. Analysis of external cardiac structures, where one observes an increase of the pulmonary trunk, RA, right ventricle and SVC.

Appearance of the connection between the $10 \mathrm{Fr}$ arterial cannula (Braile Biomédica ${ }^{\circledR}$ ) positioned in the aorta and the arterial component of the CPB, by emphasizing the difference in color of the blood with severe cyanosis, as a characteristic sign of the disease.

General aspect of the surgical field after introduction of the cannulas in aorta and vena cava moments before CPB. After its initiation, there is drastic reduction of pressure in the pulmonary trunk and the heart continues to beat, showing proper preparation of the perfusate.

Dissection of the left pulmonary artery and ductus arteriosus, appearance of the vertical vein located after the pericardial sac. Finishing of the dissection of the ductus arteriosus, passage of a 5-0 polypropylene yarn and ligation of such connection.
Correspondence address: Ulisses Alexandre Croti Hospital de Base - Faculdade de Medicina de São José do Rio Preto (FAMERP) - Avenida Brigadeiro Faria Lima, 5544 - São José do Rio Preto - SP - Brazil - CEP 15090-000.

E-mail: uacroti@uol.com.br

Article received on May $4^{\text {th }}, 2009$ Article accepted on June $3^{\text {rd }}, 2009$ 
Dissection of the posterior pericardial sac in search of the vertical vein, which was fully exposed and laced using a 5-0 polypropylene yarn. It is noted that the heart continues to beat. Heart luxation and presentation for wide dissection, which remains until perfect identification of the four pulmonary veins and the collector sac. After approximation of the image, the site of incision in the collector sac and LA is shown, which involves significant portion of the atrial appendage.

Aortic clamping, opening of the RA, introduction of the suction in the LA through the foramen ovale in the interatrial septum. Administration of hypothermic antegrade blood cardioplegia at $4^{\circ} \mathrm{C}$.

Anterior-superior luxation of the heart to appropriate exposure, two-point ligation of vertical vein using 5-0 polypropylene yarn, with one point more proximal to the collector sac and another proximal to the innominate vein, the latter with care to avoid narrow such vein. Section of the vertical vein, suture of edges using 6-0 polypropylene yarn.

Total circulatory arrest was requested at $20^{\circ} \mathrm{C}$ and the best sites for incisions in the collector sac and LA were analyzed. Incision in the collector sac using a No. 11 scalpel blade and extension using an iris scissors. It was requested to the anesthesiologist to inflate the patient's lungs so that to avoid returning of the blood by the pulmonary veins thus becoming the operative field pleasing and easy to handle. Exploring of the four pulmonary veins in order to verify the correct positioning of the opening in the collector sac, incision in the atrial appendage toward the hypoplastic LA, adapting to the measures of the edges to be anastomosed (Figure 1).

Anastomosis was initiated between the collector sac and the LA using 6-0 polydioxanone yarn (PDS - Ethicon $\left.{ }^{\circledR}\right)$, an absorbable yarn to allow the growth of structures.

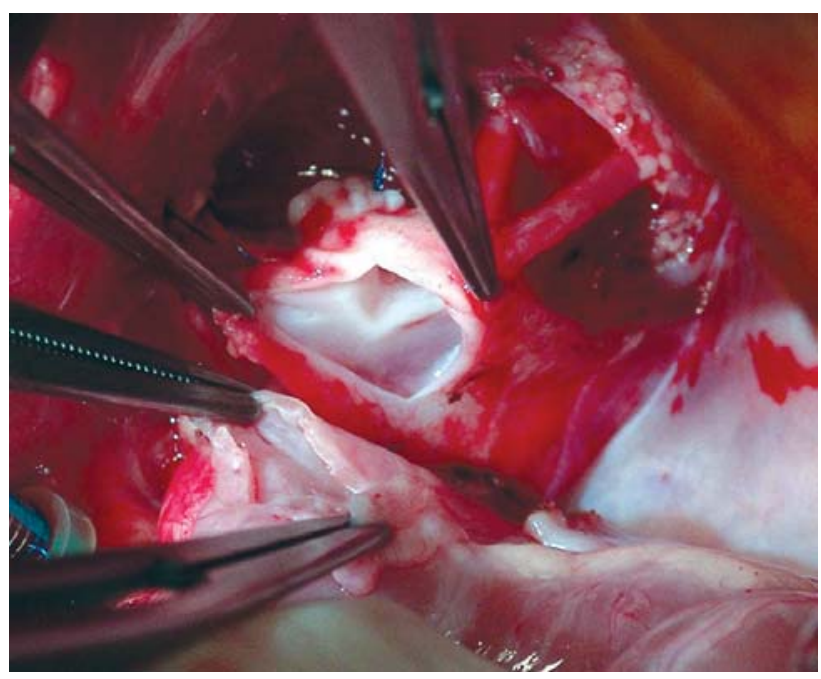

Fig. 1 - Incisions performed in the posterior wall of the left atrium and anterior wall of the collector sac after section of the vertical vein
Attention should be taken to perform a suture carefully, including the minimum necessary of edges and avoiding the proximity to the pulmonary veins, then providing less risk of late stenosis of such veins (Figure 2).

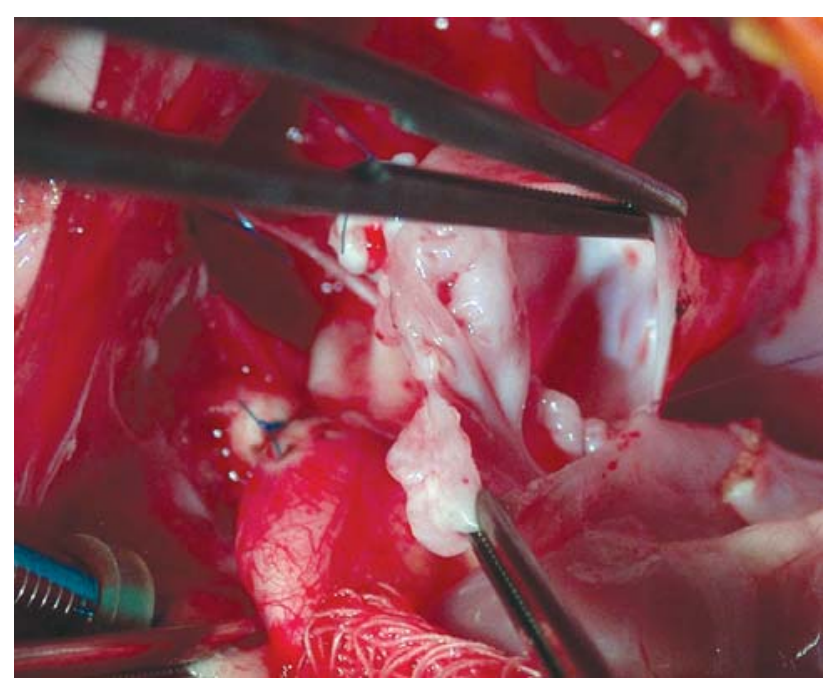

Fig. 2 - Detail of the anastomosis between the left atrium and the collector sac using 6-0 polydioxanone yarn (PDS - Ethicon $\left.{ }^{\circledR}\right)$

Finishing of the anastomosis and exposure of the general appearance of the structures.

Repositioning of the heart to the normal position, opening of the RA with expansion of the incision and resection of the oval fossa. Closure of the IAC with large bovine pericardial patch sutured with polypropylene 6-0. This patch aims to enlarge the left atrial cavity, favoring the immediate postoperative cares. Small enlargement of the interatrial septum is performed in the upper portion to adapt the patch. At the end of the suture, maneuver to remove the air of the left cavities is also performed. Suture of RA using aortic forceps removed and the heart starting contractions.

Final appearance with the aid of CPB and after reversal of heparin moments before sternotomy.

\section{REFERENCES}

1. Pinto Júnior VC, Rodrigues LC, Muniz CR. Reflexões sobre a formulação de política de atenção cardiovascular pediátrica no Brasil. Rev Bras Cir Cardiovasc. 2009;24(1):73-80.

2. Phillips SJ, Kongtahworn C, Zeff RH, Skinner JR, Chandramouli B, Gay JH. Correction of total anomalous pulmonary venous connection below the diaphragm. Ann Thorac Surg. 1990;49(5):734-9.

3. Kanter KR. Surgical repair of total anomalous pulmonary venous connection. Semin Thorac Cardiovasc Surg Pediatr Card Surg Annu. 2006;9(1):40-4. 